\title{
A Qualitative Inquiry into Students' Transformative Learning Experiences in Old Havana's Escuela Taller
}

\author{
Elizabeth A. Gilblom ${ }^{1}$ \& Jonathan E. Messemer ${ }^{2}$ \\ ${ }^{1}$ Assistant Professor, School of Education, North Dakota State University, Fargo, USA \\ ${ }^{2}$ Associate Professor, Counseling, Administration, Supervision \& Adult Learning Department, Cleveland State \\ University, Cleveland, USA \\ Correspondence: Elizabeth A. Gilblom, North Dakota State University, School of Education, FLC 210D NDSU \\ Dept. 2625, P.O. Box 6050, Fargo, ND 58108-6050 E-mail: elizabeth.gilblom@NDSU.edu
}

Received: December 23, 2019 Accepted: January 27, 2020 Online Published: February 24, 2020

doi:10.5539/jel.v9n2p104 URL: https://doi.org/10.5539/jel.v9n2p104

\begin{abstract}
This qualitative study employs transformative learning theory to investigate the learning experiences of 18 current students and graduates of Escuela Taller 'Gaspar de Melchor de Jovellanos' (ET) in Old Havana, Cuba. ET is a tuition-free, skilled-trades program that trains adult learners with limited economic resources and opportunities to conserve and restore cultural heritage, including historic structures, artwork and ironwork. The purpose of this study was to determine if and how participants transformed as a result of attending ET. Participants experienced professional and personal transformations that they attributed to learning a trade, learning how to collaborate, rediscovering their Cuban heritage, and participating in the restoration of Old Havana. The findings also underscore the significance of becoming cultural agents, who they define as individuals who experienced transformations from attending ET who support the transformations of others in their local communities by educating them about the significance and value of Cuban cultural heritage.
\end{abstract}

Keywords: artists, Cuba, cultural heritage, international vocational training programs, Old Havana, personal development, professional trades, skilled-trades program, transformative learning

\section{Introduction}

For nearly half a century, the theory of transformative learning has been discussed, hypothesized, and empirically researched by many adult education scholars. Most empirical research discusses transformative learning theories that are frequently grounded within formal teacher-centered learning contexts (Shor, Cattaneo, \& Calton, 2017) and typically focus on higher education (Sawatsky, Beckman, \& Hafferty, 2017; Troop, 2017), workplace development (Choy, 2009; Heckelman, Unger, \& Garofano, 2013; Poutiatine, 2009; Wilhelmson, Moström-Åberg, Backström, \& Köping-Olsson, 2015), and/or other market driven areas that address a specific problem-oriented matter (Kitchenham, 2006). This problem centered approach to transformative learning research seeks to study the social and cultural change in society (Gordon, 2006; Illeris, 2004; Pololi, Krupat, Schnell, \& Kern, 2013) or personal change (Heckelman et al., 2013; Poutiatine, 2009; Whitelaw, Sears, \& Campbell, 2004) in adult learners' values, beliefs, and/or behavior(s). What is less studied is the transformative learning experiences of adults in vocational training programs in international contexts.

This study investigates the transformative learning experiences of adult learners enrolled in a vocational training program located in Old Havana, Cuba. Translated as the 'Workshop Schools,' Escuelas Taller (ET) is a skilled-training program that exists primarily in Latin America that provides training and employment for adults in both urban and rural areas who have limited resources or who lack training opportunities. ET teaches students the skills necessary to conserve and restore cultural heritage, including historic buildings, artwork, ironwork, glasswork, and furniture, in their local communities. Students become general restoration specialists, ironworkers, glassworkers, archeologists and other skilled tradespeople.

\section{Purpose of the Study}

The purpose of this research was to produce an in-depth inquiry into the transformative learning experiences of Cuban adult learners of Escuela Taller 'Gaspar de Melchor de Jovellanos' in Old Havana, Cuba. The researcher sought to understand the following questions: 
How do students and graduates at ET believe they have changed as a result of attending ET? What experiences at ET facilitated their transformative learning experiences?

\section{Significance of Study}

This study contributes to the literature by investigating the transformative learning experiences of students and graduates of Escuela Taller 'Gaspar de Melchor de Jovellanos' in Old Havana, Cuba. While ET has existed for over 30 years, limited research exists about the ET program outside of publications produced by administrators and government organizations. Also, there are few studies about the experiences of adult learners who currently attend, graduated from or teach at ET. This study offers a site-based understanding of how current students, graduates of ET make sense of their transformative learning experiences in Old Havana. Examining the experiences of current students, graduates and teachers at ET is important because their experiences are largely unknown. Their experiences contribute to the larger discussion of not only ET as a program, but also how transformative learning experiences occur in Cuban vocational training programs.

\section{Literature Review}

\subsection{The Escuelas Taller Program}

ET is a training program conceptualized by José María Pérez González, known as Peridis, in 1985 during a period in which unemployed, Spanish youth lacked training and job prospects (ABC, 2017). The declining presence of traditional artisans in Spain and the pressing need to conserve the artistic, cultural and natural heritage inspired Peridis to develop a training and employment center in which these unemployed individuals could learn a trade and conserve or restore Spanish built heritage (AECID, 2015). In 1991, the Agencia Española de Cooperación Internacional para el Desarrollo (AECID), the Spanish Agency for International Cooperation for Development, created the official ET model that was designed to combat poverty with employment and promote social inclusion (AECID, 2016).

The mission of ET is to train people between the ages of 18 and 25 in traditional trades through a pedagogical approach that integrates theory and practice and emphasizes a sense of identity and the promotion of cultural heritage (AECID, 2015). During the two-year program, students engage in a practical, hands-on application approach to learn a traditional trade, such as ironwork, mural restoration, general restoration, carpentry and glasswork. During the day, students learn theory in a classroom and in the afternoon, students retreat to a workshop where they practice with materials. Students also practice their restoration and conservation skills in their local communities. Currently, students at Escuela Taller 'Gaspar de Melchor de Jovellanos' in Old Havana, the historical center of the Cuban capital of Havana, are working to restore and conserve El Capitolio, the National Capitol Building.

Most students find permanent employment and socioeconomic stability after graduation. From 1991 to 2014, 266 ET are in 67 cities in 24 countries, including Cuba, Mexico, Peru, Guatemala, Belize, and the Philippines (AECID, 2015). Latin America has 249 ET with 26,220 graduates, while Africa and Asia have 17 ET and 1,163 graduates (AECID 2015). Many Escuelas Taller are developed in or near UNESCO World Heritage sites. Gilblom (2019) offers a detailed history of the origin and development of ET, and an investigation of students' experiences of learning how to conserve and restore cultural heritage in Old Havana, Cuba.

The ET training programs may be understood as cognitive apprenticeships for adult learners as described by Brown, Collins, \& Duguid (1989). They suggest that "Cognitive apprenticeship methods try to enculturate [learners] into authentic practices through activity and social interaction in a way similar to that evident - and evidently successful - in craft apprenticeship" (p. 37). ET may be considered a non-formal training program, which are often "associated with international development programs designed to improve the living conditions of people in developing countries through community projects and training programs" (Merriam, Caffarella, \& Baumgartner, 2007, p. 31).

\subsection{Escuelas Taller as Cultural Agents}

Given that ET provides students with the training necessary to conserve and restore cultural heritage in their communities, and because they provide training spaces for individuals without educational and job prospects, ET sees their training centers as "cultural agents, [that] intervene in the safeguarding of heritage" (AECID, $2015 \mathrm{p}$. 112). As cultural agents, ET provides skills to students that give them job opportunities and helps them to overcome their marginalized positions in society (Red de Escuelas Taller de America Latina, 2015). Additionally, ET supports the material recovery of the local environment (Red de Escuelas Taller de America Latina, 2015). Therefore, ET identifies as a cultural agent that provides a "turning point in the lives of many young people with limited opportunities to education" and it is also a "turning point" for the local city that requires conservation 
and restoration (Red de Escuelas Taller de America Latina, 2015, p. 35).

\subsection{Transformative Learning Theory and the Disorienting Dilemma}

According to Mezirow (2000) transformative learning begins with a disorienting dilemma that catalyzes a self-examination of one's underlying assumptions. Essentially, learners who have a transformative learning experience a shift of their worldview. As Clark (1993) states, "In short, transformational learning shapes people; they are different afterward, in ways both they and others can recognize" (p. 47). Through transformative learning, Mezirow (2000) states that individuals can become more autonomous, they can make better choices and become self-impowered and independent adults.

Mezirow (1990) suggests that the disorienting dilemma may include "a divorce, death of a loved one, change in job status, retirement, or other. The disorienting dilemma may be evoked by an eye-opening discussion, book, poem, or painting or by one's efforts to understand a different culture that challenges one's presuppositions" (pp. 13-14). An empirical study from Clark (1991) further found that disorienting dilemma can be the result of integrating circumstances that stimulate the adult learner to consciously or unconsciously identify something that he or she finds is missing in his or her life. Clark (1991) suggests that when the adult learner is able to identify the disorienting dilemma, the transformative process begins.

Brookfield (1987) suggests that transformative learning requires adult learners to become critical thinkers regarding their experiences and personal, family, work, community, and political beliefs. Cranton (1992) suggests, "The questioning of previously accepted assumptions comprises the process of critical reflection, and when an individual question his or her own assumptions, it is critical self-reflection" (p. 149). Taylor (2008) suggests "transformative learning is as much about social change as individual transformation" (p. 10).

\subsection{Transformative Learning in International Contexts}

There are few recent studies that examine transformative learning in international contexts. DeGennaro (2018) recently studied indigenous young adults in Guatemala regarding how they participate in a self-directed, technology-based learning activities that were designed to encourage transformative praxis. She found that young adults "encounter, negotiate and struggle with their new role of directing and defining their learning ... these illustrations begin to reveal how youth vacillate between oppressive and liberating educational practices" (p. 241). DeGennaro also found "that participants expect to experience 'normalized' organizational structures. Often, there remains an unconscious assumption that those in 'authority' positions create the vision and structure, and the 'powerless' follow the inscribed rules" (p. 242).

Merriam and Ntseane (2008) sought to study how culture shapes the transformative learning process within Botswana. Their qualitative investigation suggests that there are three cultural factors that influence the transformative learning process. First, they suggest that "it is an individual experience, contextualized by the individual's interpretation and meaning making of the environment and culture" (p. 195). Additionally, they suggest that "a sense of community responsibility and relationships" (p. 195) and "gender roles, and in particular women's roles" (p. 195) affected the transformative learning process. In a study of indigenous college students, Chen (2012) found that they entered college with low self-esteem which resulted in a stigmatized personal identity compared to the non-indigenous students. The findings also suggest that indigenous college students who participated in the non-formal tribal services program and native student clubs those students developed an increase in "their positive self-concepts, interpersonal relationships, and ethnic and cultural identities" (p. 161). The perceptions of the indigenous college students' personal transformations coincided with the development of meaningful student relationships that aided their personal career choices.

Duveskog, Friis-Hansen, and Taylor (2011) conducted a study of adult learners participating in Farmer Field Schools in the rural areas in Kenya, Africa. The findings suggest that the participants demonstrated a strong "personal transformation, changes in gender roles and relations, customs and traditions, and community relations, and an increase in household economic development" (p. 1529). They found that the Farm Field School participants developed a significant "transformation of self (psychological) as well as in the change in how the informants in this study perceived gender roles in the family (socio-linguistic)" (p. 1540). This study also suggests that the adult learners demonstrated "greater self-efficacy and confidence in themselves as farmers and as contributing members of their households and community, consistent with previous research in the field of transformative learning" (p. 1540). Duveskog, Friis-Hansen, and Taylor also discovered that "in contrast to Western studies of transformative learning, the transformation described by these participants did not emphasize greater autonomy and self-directedness" (p. 1540). Additionally, the Farm Field School had a liberating impact upon women, "as they acquired greater opportunities to engage in decision-making and economic activity" (p. 1541). They also suggest that the findings seem "to reveal that indicators of transformative learning that are 
unique to the cultural context of Africa ... the epistemological shift seems unique to this setting (a shift to empiricism), and not something that has been revealed in any of the Western studies" (p. 1540).

While several studies exist detailing the transformative learning experiences of adult learners in international contexts, no studies exist that explore the transformative learning experiences of adult learners in Cuba. Specifically, there is a lack of studies that investigate the transformative learning experiences of adult learners enrolled in international vocational training programs, including Escuelas Taller.

\section{Methodology}

\subsection{Rationale for Qualitative Research}

Qualitative research is needed to explore the rich and complex understandings and experiences of current adult learners at ET. Merriam (2009) suggests that qualitative researchers are interested in understanding the meanings people have constructed, or how people make sense of their experiences within the world. A qualitative research design was deemed the most suitable for this study because it allowed the researchers to enter the participants' frames of reference, uncover their interpretations of their learning experiences at ET, and understand the meaning of their experiences. In addition, Taylor and Laros (2014) recommend that the qualitative exploration of transformative learning seek to enhance our awareness within different contexts, such as in this case of ET in Cuba.

\subsection{Research Setting and Participants}

The article is based on the data collected from a one-month long investigation of the experiences of students, teachers and administrators at Escuela Taller 'Gaspar de Melchor de Jovellanos' in Old Havana, Cuba. The ET in Old Havana, Cuba was chosen as the research area rather than ET located in Camagüey, Trinidad, Santiago de Cuba, and Cienfuegos because Escuela Taller 'Gaspar de Melchor de Jovellanos' was the first ET developed in Cuba and it has more graduates over more years than the other ET in Cuba. Since its founding in 1992, nearly 1,000 students have graduated in fourteen specialties. A major strength of this research is that there was a wide sampling of student experiences throughout the existence of ET from the first graduating class in 1994 to a graduate from 2013. The wealth of graduates in Old Havana over the past 25 years in a variety of specialties provides a range of experiences and stratified sample that benefit this qualitative study of students' and graduates' experiences at ET.

A total of 18 students, graduates, instructors and administrators participated in interviews either alone, in pairs or with a focus group. The participants were a result of snowball sampling in which participants referred the researcher to other potential participants. The researcher spoke with administrators and instructors who never attended ET as students to explore the student experience from another angle. A Cuban translator was present during all interviews and translated each interview from Spanish to English. All interviews were audio recorded with the participants' permissions.

\subsection{Data Collection and Analysis}

Analytic memos, photos and in-depth, semi-structured interviews encompass the primary means of data collection. The photos are used in this manuscript in order to bring to life the cultural heritage and restoration work performed by the Cuban adult learners. This approach to use photographs was influenced by the works of Elvy (2004) and Lawrence and Cranton (2009) in their transformative research on adult learning.

This study used the semi-structured interview approach because it provides rich accounts of the participants' experiences of being students and graduates of Escuela Taller 'Gaspar de Melchor de Jovellanos' in Old Havana, Cuba. The interviews used a semi-structured protocol because the study is exploratory. This approach permitted students to deviate from narrow topics and explore other avenues of thought. An interview guide was utilized to provide for consistency regarding discussion of several key areas, while preserving the flexibility to re-word and re-order questions or add additional probes as needed. The questions investigated notions of personal transformation, professional transformation, their general challenges and experiences and the value of cultural heritage. Follow-up questions that were provoked by the participant's statements were used as needed to answer the research questions. The interviews ranged in length from one hour to two hours. The initial question opening each individual interview was as follows: What specialization did you choose at Escuela Taller and what led you to this program? Other questions posed to students include: How have you personally changed as a result of your experiences at Escuela Taller? How has your professional life changed from attending Escuela Taller? The researcher and participants also discussed the fact that ET sees their schools as cultural agents. From this conversation, participants were asked if they saw themselves as cultural agents.

A verbatim text was transcribed using audiotapes of the interviews and Braun and Clarke's (2013) method was 
used for transcription. Saldaña's (2013) descriptive coding process was used to analyze the transcriptions. The researcher used analytic memos to reflect on the data and to connect codes with the research questions. Additionally, a reflective journal served as a source for data and was integral to interpretation and analysis of the data. The journal helped the researcher to refine the information and maximize "opportunit[ies] for triangulation of data sets at multiple levels" (Janesick, 2004, p. 143).

\subsection{Interpretive Framework}

The research design was guided by social constructivism. Social constructivism adheres to a relativist position that "posits multiple, equally valid social realities" (Haverkamp \& Young, 2007, p. 268). Constructivists respect individual values and lived experiences and believe in pluralistic, interpretive, open-ended, and contextualized perspectives toward reality (Creswell, 2013; Haverkamp \& Young, 2007). Adopting a constructivist epistemological approach affords the researcher flexibility and rigor to gather co-constructed perspectives and opinions through interactive and comprehensive interviews. It also allows the researcher to analyze, interpret and triangulate the perspectives of participants through identification of concepts and categories from the thick and rich data.

\subsection{Ethical Considerations and Trustworthiness}

The researcher ensured the trustworthiness of the findings they gathered from the field by reciprocating with the participants, presenting themselves honestly and describing the purpose of the study (Creswell, 2013). Care was taken to explain to the participants that the researcher was not a representative of the United States government and that this research project was our own and not associated with any government organization. Fictitious names were used in the transcripts to protect the privacy of all participants and the researcher assured them that their real names would not be disclosed. The participants gave written informed consent and agreed to the audio recording of the interviews that were transcribed into English and reviewed by a second Spanish/English translator in the United States. Participants were not provided monetary compensation for participating. All participants were advised that they have the right to withdraw from the study at any time. This study was approved by an Internal Review Board.

Triangulation (Denzin \& Lincoln, 2011) of data sources, diverse perspectives and reflexive memos ensured the trustworthiness of this study. Data from the reflective journal was shared with a colleague who is a critical researcher and was also conducting qualitative research in Cuba. The role this colleague played in this research was for "peer examination", or to gain different perspectives on the same set of data (Merriam, 1998, p. 204). The critical researcher helped me to see what I may be overlooking or not accounting for during data analysis. The researcher also met with several participants after the interviews to revisit some of the data collected and discussions with the Spanish/English translator also helped clarify, verify and provide alternative perspectives of the data.

\section{Findings}

In the sections that follow, the researchers detail the recurring themes throughout data collection. The findings are illustrated with photos and quotes from participants derived from the semi-structured interviews. Participants are referred to by their specialization and their status as a student, graduate or teacher in order to preserve their anonymity.

\subsection{Becoming Cultural Agents}

While ET sees their schools as cultural agents, the participants saw themselves as cultural agents as a result of their learning experiences at ET. A general restoration student remarked that a cultural agent is "a person who maintains, restores and preserves the works of his own country, that identify his country. Built heritage, for example." One of his peers added, "From what I have learned at school, it is a person who manages in a certain way, takes care of, protects everything that has to do with the cultural world in the place where they live. In my case, the Historical Center (Old Havana). And I feel like that, that I am playing that role because of the work I've been doing."

Many participants emphasized the cultural pride resulting from their newfound knowledge of Cuban heritage and restoration techniques. Another general restoration student connected the concept of a cultural agent to feelings of pride and fulfillment. In his perspective, to be a cultural agent is "to leave your footprint through your time, to be part of a conservation of a piece because all of the things we are working on are part of the cultural heritage of Cuba. All the work we've been doing is part of the history of Cuba and we feel proud. Sometimes I tell my girlfriend or my dad or my brother, 'I worked over there. I did this.' It's something that fulfills you."

Participants also described how their perceptions of Cuban heritage shifted while working in Old Havana. One 
participant commented that his training has permitted him "to understand the need to value the heritage we have in Cuba and to protect it." Another general restoration student added, "I feel I identify as a Cuban [when I am] working at places like the Capitolio or the Inglaterra Hotel (a historic, colonial-era hotel built in 1875 that is the oldest hotel in Cuba), places that are so important, so representative of Havana." Some participants remarked that being a cultural agent is an honorable position in society. One general restoration student remarked, "I feel that I am a cultural agent because I am helping my country to preserve its own heritage. I feel that it is a dignified role...to preserve my country's heritage." Figure 1 is a photo of Plaza Vieja in Old Havana. The buildings surrounding this plaza were restored by the students and graduates of ET.

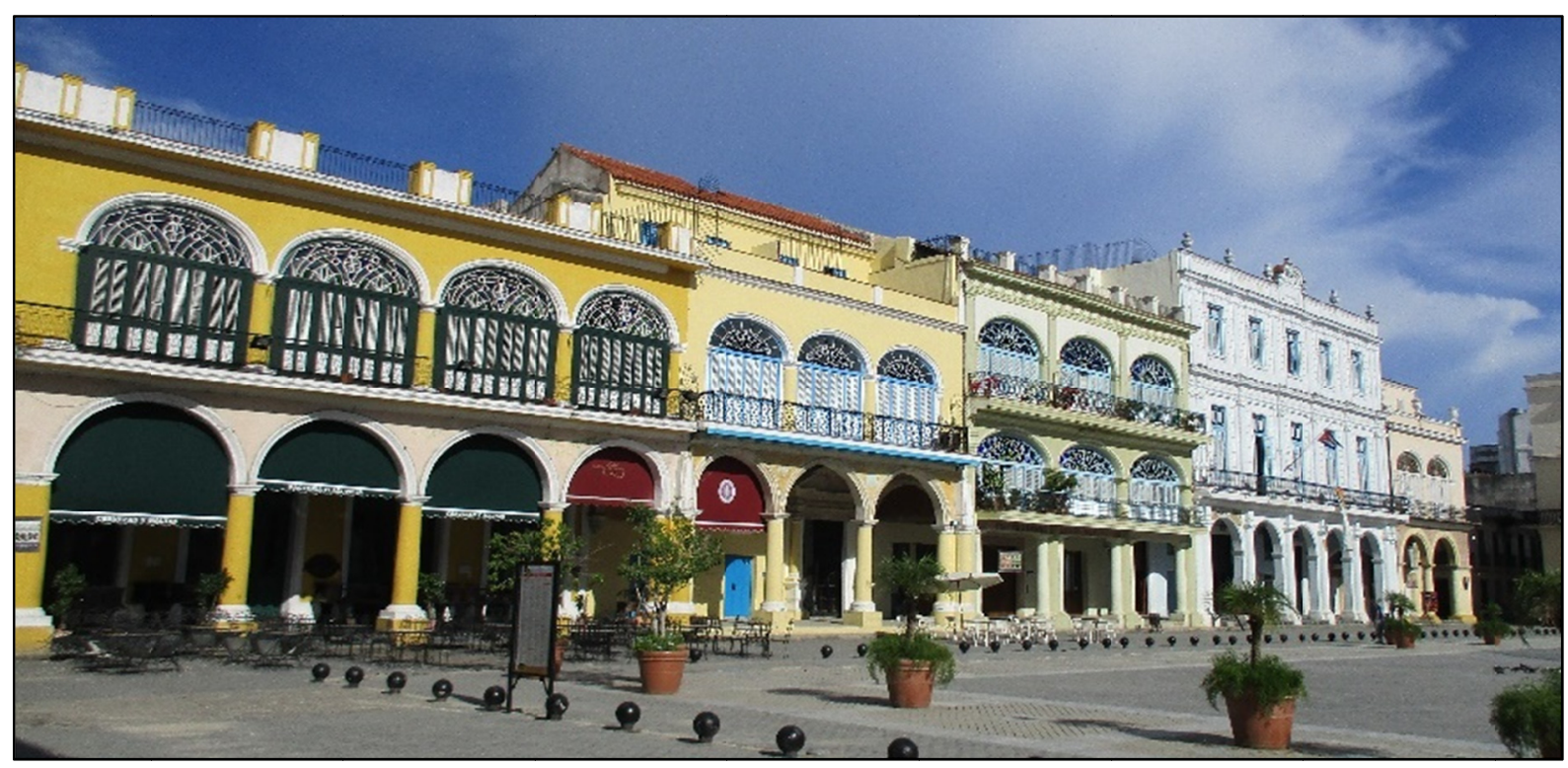

Figure 1. Built heritage restored in Plaza Vieja, Old Havana by students and graduates of Escuela Taller

\subsubsection{Sharing Knowledge as a Cultural Agent}

Participants indicated that a significant responsibility of cultural agents is to share knowledge about Cuban heritage with others. One ironworker stressed that it is his "moral obligation to educate others" about cultural heritage. Additionally, an archeology specialist expressed that the primary responsibility of cultural agents is "to impact others...It's the intersection between our training and the training of the rest of the people." Another ironworker remarked that being a cultural agent means "passing good energy to another. That energy grows and goes to other people."

All participants expressed that they share their appreciation, knowledge and enthusiasm for Cuban heritage and history with their friends and families, individuals who may not otherwise be exposed to heritage and that these individuals have benefitted from learning about Cuban heritage. An ironworker who is now a sculptor explained how a community changes when ET graduates share their knowledge with others. "I saw in a way that we can change the neighborhood. We create projects...for instance, [an ET graduate] has his own workshop, but I know [the graduate's neighbor] here from this building who comes and looks at his work and tries to learn about what he's doing. There is an exchange. That's a cultural agent."

An ironworker who is also a drawing instructor at ET described how cultural agents transform others into cultural agents: "A cultural agent is someone who is always trying to open that door for others. There are many people in [the local community] who don't have that knowledge about the artistic side [of cultural heritage], but they have it in them and when they start talking with [graduates or current students] ... they start becoming cultural agents, too."

\subsection{Learning to Collaborate}

All participants described the ways in which working on large scale restoration projects strengthened their ability to work with others. An archeology specialist indicated how listening skills are connected to teamwork. "First you learn how to listen. It helps you to understand and to be flexible as a person. We work, at least my team 
works, in a joint venture with the personal spirit and professional spirit." An ironworker discussed how his personal confidence grew and how his training taught him how to interact with others. "I feel proud of my job, of what I can do as a professional and a worker of [ET]. That gives me the confidence I need to be here [in this interview] talking about my experiences. I've grown not only professionally, but also personally...I've learned how to have this conversation. I've learned how to communicate and how important that is."

\subsection{Finding Purpose}

The participants indicated that attending ET helped them to discover their purpose in their life. One metalwork student remarked, "In my case, I found my vocation in life, something I really wanted to do when I found this school." Participants also described how they have become better people. A general restoration graduate who also teaches discussed how the training "helps you to become a person...It's much more...For instance, it gives you experience and you're educating yourself to be a good person, not a bad one." One ironworker described how he does not drink alcohol because ET gave him purpose: "I don't like to drink. I don't do that because I had the chance to be at that school. I went to class every single day."

\subsection{Professional Transformations}

The participants indicated that they experienced professional transformation and economic stability from attending ET. One participant stated that the most significant outcome is learning a skill because once an individual learns a skill, "he can take advantage of it for the rest of his life. He can use that skill for future work." Participants identified the professional opportunities that they have. One ironworker emphasized the importance of becoming a master of a chosen skill because when an individual "make[s] good quality work [they] have more possibilities to work with [other skilled tradespeople]." He remarked that he was offered opportunities by prominent people due to his exceptional ironworking skills. He was selected to restore the most challenging part of a building's balconies because of his skill level. He stated, "At that restoration project, I restored the balconies. I actually worked on the technical part, which was the hardest part, and I don't want to look like I'm showing off, but only a few people can do that. It was a lot of responsibility."

Another ironworker described how the director of ET asked him to work on a special project. "[The director] asked me to be a worker at Las Teresas Convent...the person who is in charge of Las Teresas is an architect, he talked to me to see if I can do the things that people usually don't do in the city...colonial locks...that's not a typical job. By request I started doing locks, keys imitating the style from the last century. Completely functional locks."

\subsubsection{Jobs with Private Entities}

Graduates of ET primarily work on state sponsored restoration projects managed by the Oficina del Historiador de la Ciudad de la Habana (OHCH), translated as the Office of the Historian of the City of Havana. The OHCH determines which built heritage within Old Havana will be restored, such as the Capitolio, the project site at which current ET students are learning to restore heritage. After graduation, graduates commit to working on $\mathrm{OHCH}$ projects for 3 years, after which graduates may branch out and work on non-government-sponsored projects. Some participants who have several years of experience working in restoration projects discussed their experience working for privately-owned entities that are not associated with the government. One ironworker remarked that he was hired by an individual who was building a hotel in Old Havana to craft balconies, stairs and other metal pieces to fit the 19th century décor. Other graduates discussed their partnerships with local vendors, including one ironworker who crafted metal flower pot hangers for a flower shop and metal lamps used as decorations in a fine foods store.

\subsection{Using Restoration Skills in their Homes and in Art}

Participants indicated that they use their skills to improve their homes and to create art. One stoneworker said she learned how to restore main walls, arches and columns at ET and, with these skills, she restored the walls and roof of her house. She remarked, "We learned how to fix and rebuild walls that were broken. This helps me a lot because I of a lot of work in my own house." Some graduates remarked that local Cubans have hired them to renovate their homes, including the walls, crown moldings and roofs. Other participants described using their restoration skills to create artwork. One ironworker presented a violin art piece he crafted from iron (Figure 2). He stated that he had made several and had sold one to a visiting Canadian diplomat. Another ironworker, who is now an artist, showed me a mixed-media piece using recycled materials that represented a ciudadela, a poor town (Figure 3). He stated, "what catches the people's attention [about my art] ... they always ask me, 'How can you do that?' because it's impossible to join these [different] materials, they are not compatible. It is a practice I do in life. The concept of my work comes from the theory that you can do anything that you wish." 


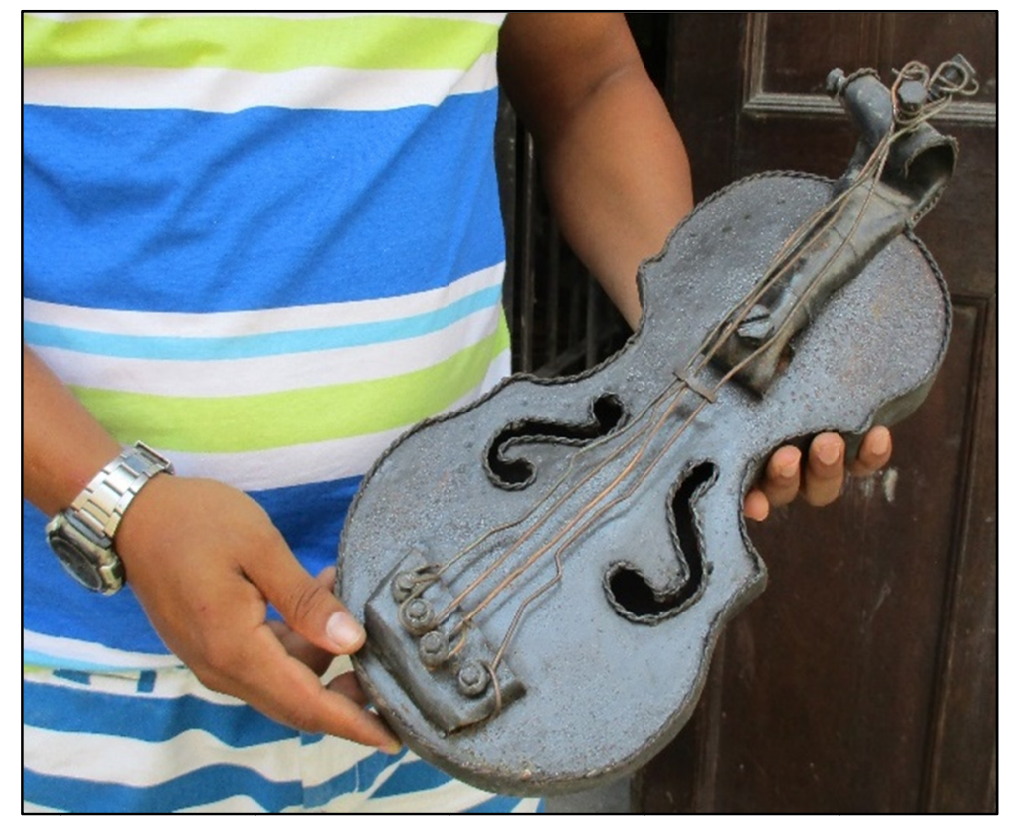

Figure 2. Handcrafted iron violin made by an ironworker from Escuela Taller

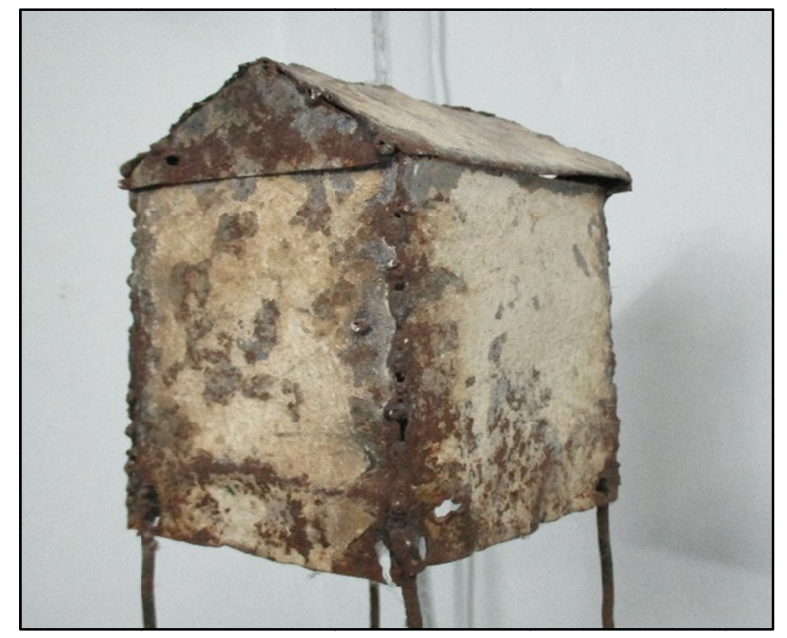

Figure 3. Handcrafted art piece of a ciudadela by an ironworker from Escuela Taller

\section{Discussion}

The purpose of this research was to explore the transformative learning experiences of adult learners who attend or graduated from ET. The findings indicated that they experience meaningful personal and professional transformations from attending ET. Participants describe their transformation in terms of how their community changes because of their contributions, including the restoration of heritage and sharing knowledge with others. They also discussed how they have developed self-confidence and pride from their role as restoration workers and cultural agents in Old Havana. Moreover, their personal and professional transformations align with the transformative learning experiences of individuals in international contexts.

As Brookfield (1987) suggests that transformative learning requires adult learners to become critical thinkers, the participants demonstrated that they had transformative learning experience because they critically thought about themselves, their role in their community and the community itself. First, the findings indicated that they perceived themselves as cultural agents who have a vital role in their communities. Taylor's (2008) suggestion 
that "transformative learning is as much about social change as individual transformation," coincides with the participants' transformative experiences. (p. 10). The participants emphasized how their neighborhoods change when they encourage the transformation of the people around them by passing on knowledge about Cuban heritage and restoration techniques. As ET offers training spaces for individuals to become skilled workers who would not otherwise have access to learning opportunities, participants similarly provide "training spaces" through personal discussions about cultural heritage with the people in their families and communities, individuals who would not otherwise have access to this information.

Additionally, similar to Merriam's and Ntseane's (2008) study that suggested how a sense of community responsibility and relationships affected the transformative learning process, the participants mentioned their "moral obligation to educate others", they described cultural agents as the "intersection between our training and the training of the rest of the people" and "passing good energy" to others and how this "energy grows and goes to other people." The participants recognized other peoples' potential to learn about Cuban cultural heritage and to even learn some restoration techniques. One participant stated that many people in his local community "have it in them" to learn restoration techniques and when they learn, "they start becoming cultural agents, too." They contend that by sharing their knowledge about Cuban heritage and restoration skills with others, they are transforming individuals who have not been students at ET into cultural agents and that this exchange of knowledge "can change the neighborhood". Therefore, the outcome of the participants' transformations is not solely the self-empowerment or autonomy that Mezirow (2000) describes in transformative learning. Rather, the result is focused on contributing to and bonding with the local community.

However, the participants discussed their greater self-efficacy, confidence, and a sense of importance in seeing themselves as workers, artists, and as cultural agents. These findings coincided with Duveskog, Friis-Hansen and Taylor (2011) and Chen's (2012) respective studies. They felt pride in their abilities, community role and cultural identity from becoming highly-skilled restoration workers who contributed their local community and who share their knowledge with others. Participants indicated that their participation in the restoration of Old Havana is a "dignified" role that "fulfills" them. Another participant remarked that restoring building in Old Havana equates "to leav[ing] your footprint through your time," a statement that echoes Red de Escuelas Taller de America Latina (2015) claim that students become empowered, skilled tradespeople through their participation in the recovery of cultural heritage. These findings suggest that participants understood that they were becoming part of the history and legacy of the cultural heritage they restored in Old Havana, their hometown.

Another element of the professional and personal transformations resulting from ET training is the development of soft skills. The participants' skill development extends far beyond the hard skills related to restoring built heritage, murals and ironwork. As one participant remarked, the first think students learn while at ET is "learn[ing] how to listen. It helps you to understand and to be flexible as a person." Each participant emphasized how they learned to collaborate, listen and communicate with the different parties on a restoration site and how these soft skills are an integral part of their work because it promotes the success of a project.

The professional transformations participants experienced include being offered unique job opportunities, including working with private entities. Highly-skilled individuals were offered exclusive work opportunities, job prospects that less skilled individuals would not have. Additionally, graduates have transferred skills they learned at ET to other contexts. The technically and artistically gifted graduates are highly sought after by café owners, home owners, museums, government-owned shops, and hotel developers who hire them to rebuild or recreate buildings and elements that match the style of Old Havana. They have found innovative ways to use their skills, including starting renovation businesses, restoring their own homes, creating works of art, mentoring other artists and teaching others restoration skills and sharing their knowledge of cultural heritage.

One aspect of the findings that requires further investigation is the role of Cuban culture in the transformative learning process. Some participants stated that they feel a deeper connection to their Cuban heritage as a result of restoring cultural heritage. The participant that stated they he "identif[ies] as a Cuban" when he is working at locations that are "so representative of Cuba" recognizes the role that culture can play in the transformative learning process. Few studies examine cultural considerations in transformative learning (Merriam \& Ntseane, 2008; Ntseane, 2011). Further research that more thoroughly examines how participants' learning experiences at ET are shaped by Cuban culture is needed.

\section{Conclusion}

The students and graduates of ET are more than just tradespeople who conserve, restore and replace Cuban cultural heritage in Old Havana, they are valuable and fundamental influences in the development of modern 
Cuba. As vital assets who "leave [their] footprint[s] through [their] time," students and graduates create and restore pieces with the original techniques used by 18th and 19th century craftsman, skills that were nearly forgotten. With each restoration project, the students and graduates revitalize their own cultural heritage and become a part of its history. Students of ET experience transformations that stem from the skills they learn, but also from the confidence and pride they feel from contributing to their community as highly-skilled restoration workers and cultural agents who encourage the transformations of others.

\section{References}

ABC. (2017). Peridis, Personaje Público de Castilla y León que Mejor Comunica. Retrieved from http://www.abc.es/espana/castilla-leon/abci-peridis-personaje-publico-castilla-y-leon-mejor-comunica-2017 01251232_noticia.html

Agencia Española de Cooperación Internacional para el Desarrollo. (2015). Programas de Escuelas Taller de la Cooperación Española. Madrid. $\quad$ Retrieved from http://intercoonecta.aecid.es/Documents/Escuelas\%20Taller_Programa.pdf

Agencia Española de Cooperación Internacional para el Desarrollo. (2016). Programa De Escuelas Taller Aprender Haciendo. Retrieved from http:/www.aecid.es/Centro-Documentacion/Documentos/Divulgación/ESCUELASTALLER ONLINE.pdf

Merriam, S. B., Caffarella, R. S., \& Baumgartner, L. M. (2007). Learning in adulthood: A comprehensive guide $\left(3^{\text {rd }}\right.$ ed.). San Francisco, CA: Jossey-Bass

Braun, V., \& Clarke, V. (2013). Successful qualitative research: A practical guide for beginners. Thousand Oaks, CA: SAGE Publications.

Brookfield, S. (1987). Developing critical thinkers. San Francisco, CA: Jossey-Bass.

Brown, J. S., Collins, A., \& Duguid, P. (1989). Situated cognition and the culture of learning. Educational Researcher, 18(1), 32-42.

Chen, P. (2012). Empowering identity reconstruction of indigenous college students through transformative learning. Educational Review, 64(2), 161-180. https://doi.org/10.1080/00131911.2011.592574

Choy, S. (2009). Transformational learning in the workplace. Journal of Transformative Education, 7(1), 65-84. https://doi.org/10.1177/1541344609334720

Clark, C. M. (1991). The restructuring of meaning: An analysis of the impact of context on transformational learning. Unpublished doctoral dissertation, University of Georgia, Athens.

Clark, C. M. (1993). Transformational learning. In S. B. Merriam (Ed.), An update on adult learning theory. New Directions for Adult and Continuing Education, No. 57 (pp. 47-56). San Francisco, CA: Jossey-Bass.

Cranton, P. (1992). Working with adult learners. Toronto, Ontario: Wall \& Emerson, Inc.

Creswell, J. W. (2013). Research design: Qualitative, quantitative, and mixed methods approaches. Thousand Oaks, CA: Sage Publications.

DeGennaro, D. (2018). Toward transformative praxis: Fostering a teacher/leader/learner disposition. Journal of Transformative Education, 16(3), 220-245. https://doi.org/10.1177/1541344617736635

Denzin, N. K., \& Lincoln, Y. S. (2011). The Sage handbook of qualitative research. Thousand Oaks, CA: Sage.

Duveskog, D., Friis-Hansen, E., \& Taylor, E. W. (2011). Farm field schools in rural Kenya: A transformative learning experience. Journal of Development Studies, 47(10), 1529-1544. https://doi.org/10.1080/00220388.2011.561328

Elvy, J. C. (2004). Notes from a Cuban diary: Forty women on forty years. Journal of Transformative Education, 2(3), 173-186. https://doi.org/10.1177/1541344604265130

Freire, P. (1985). The politics of education: Culture, power, and liberation. New York, NY: Bergin \& Garvey. https://doi.org/10.1007/978-1-349-17771-4

Gilblom, E. A. (2019). "These are our beans": Learning by doing, innovation and resilience in Old Havana's Escuela Taller. International Journal of Cuban Studies, 11(2). https://doi.org/10.13169/intejcubastud.11.2.0247

Gordon, G. (2006). Transforming thinking amongst British African Caribbeans as an academically based community service contribution. Journal of Transformative Education, 4(3), 226-242. 
https://doi.org/10.1177/1541344606290369

Haverkamp, B. E., \& Young, R. A. (2007). Paradigms, purpose, and the role of the literature formulating a rationale for qualitative investigations. The Counseling Psychologist, 35(2), 265-294. https://doi.org/10.1177/0011000006292597

Heckelman, W. L., Unger, S., \& Garofano, C. (2013). Driving culture transformation during large-scale change. OD Practitioner, 45(3), 25-30.

Kitchenham, A. (2006). Teachers and technology: A transformative journey. Journal of Transformative Education, 4(3), 202-225. https://doi.org/10.1177/1541344606290947

Knowles, M. S. (1980). The modern practice of adult education: From pedagogy to andragogy (2nd ed.). New York, NY: Cambridge Books.

Lawrence, R. L., \& Cranton, P. (2009). What you see depends upon how you look: A photographic journey of transformative learning. Journal of Transformative Education, 7(4), 312-331. https://doi.org/10.1177/1541344610392378

Merriam, S. B. (1998). Qualitative research and case study applications in education. San Francisco, CA: Jossey-Bass.

Merriam, S. B. (2009). Qualitative research: A guide to design and interpretation. San Francisco, CA: Jossey-Bass.

Merriam, S. B., \& Ntseane, G. (2008). Transformational learning in Botswana: How culture shapes the process. Adult Education Quarterly, 58(3), 183-197. https://doi.org/10.1177/0741713608314087

Mezirow, J. M. (1990). How critical reflection triggers transformative learning. In J. Mezirow \& Associates (Eds.), Fostering Critical Reflection in Adulthood: A Guide to Transformative and Emancipatory Learning (pp. 1-20). San Francisco, CA: Jossey-Bass.

Mezirow, J. (2000). Learning to think like an adult: Core concepts of transformation theory. In J. Mezirow \& Associates, Learning as transformation (pp. 3-33). San Francisco, CA: Jossey-Bass.

Ntseane, P. G. (2011). Culturally sensitive transformational learning: Incorporating the Afrocentric paradigm and African feminism. Adult Education Quarterly, 61(4), 307-323.

Pololi, L. H., Krupat, E., Schnell, E. R., \& Kern, D. E. (2013). Preparing culture change agents for academic medicine in a multi-institutional consortium: The c-change learning action network. Journal of Continuing Education in the Health Professions, 33(4), 244-257. https://doi.org/10.1002/chp.21189

Poutiatine, M. I. (2009). What is transformation? Nine principles toward an understanding transformational process for transformational leadership. Journal of Transformative Education, 7(3), 189-208. https://doi.org/10.1177/1541344610385249

Red de Escuelas Taller de America Latina. (2015). Arquitectura de Restauracion: Escuelas Taller y su ambito de accion. Puebla: Red de Escuelas Taller de America Latina.

Saldaña, J. (2013). The coding manual for qualitative researchers. Los Angeles, CA: Sage Publications.

Sawatsky, A. P., Beckman, T. J., \& Hafferty, F. W. (2017). Cultural competency, professional identity formation and transformative learning. Medical Education, 51, 462-464. https://doi.org/10.1111/medu.13316

Shor, R., Cattaneo, L., \& Calton, J. (2017). Pathways of transformational service learning: Exploring the relationships between context, disorienting, dilemmas and student response. Journal of Transformative Education, 15(2), 156-173. https://doi.org/10.1177/1541344616689044

Taylor, E. W. (2008). Transformative learning theory. In S. B. Merriam (Ed.), The Third Update on Adult Learning Theory (no. 119, pp. 5-15). New Directions for Adult and Continuing Education. San Francisco, CA: Jossey-Bass. https://doi.org/10.1002/ace.301

Taylor, E. W., \& Laros, A. (2014). Researching the practice of fostering transformative learning: Lessons learned from the study of Andragogy. Journal of Transformative Education, 12(2), 134-147. https://doi.org/10.1177/1541344614548589

Troop, M. (2017). Creativity as a driver for transformative learning: Portraits of teaching and learning in a contemporary curriculum course. Journal of Transformative Education, 15(3), 203-222. https://doi.org/10.1177/1541344617692772 
Whitelaw, C., Sears, M., \& Campbell, K. (2004). Transformative learning in a faculty professional development context. Journal of Transformative Education, 2(1), 9-27. https://doi.org/10.1177/1541344603259314

Wilhelmson, L., Moström-Åberg, M., Backström, T., \& Köping-Olsson, B. (2015). Enabling transformative learning in the workplace: An educative research intervention. Journal of Transformative Education, 13(3), 219-238. https://doi.org/10.1177/1541344615574599

\section{Copyrights}

Copyright for this article is retained by the author, with first publication rights granted to the journal.

This is an open-access article distributed under the terms and conditions of the Creative Commons Attribution license (http://creativecommons.org/licenses/by/4.0/). 